\title{
MASSIVE SIMULATION OF COMPLEX BEHAVIOUR
}

\begin{abstract}
The promise of Newtonian science to create a universal precise explanation of all phenomena seems to be out-dated. "Cutting through complexity" may kill potential solutions. The complexity of real phenomena should be accepted and at best tamed by appropriate techniques. Complexity, a recent megatrend in the sciences, may effectuate another scientific revolution.

Keywords: vagueness, complexity, simulation.
\end{abstract}

\section{Beware of oversimplified models}

In many fields of research in the natural or social sciences, there are no linear causal mechanisms that lead indubitably to the desired result. In the quest for a formal elegancy, reductive models tend to be simpler than is reasonable. They turn out to be not just inadequate, but oftentimes delusive. Let us illustrate this wide-spread phenomenon by an example from finance. Finance is part of economics, i.e. a social science, but it makes extensive use of quantitative methods typical for the (natural) sciences. Its cross nature makes it an approriate example for the general trend.

At the beginning of our century, there was a general blindness of mainstream economics to the very possibility of systematic failures in a market economy. It is perhaps no over-claim to say that economists thought that they had resolved their internal disputes. After 2008, of course, the quarrels about theoretical issues are back and they are more vivid than ever. Important questions concern the role of mathematical methods in economic theory building. Ambitious economic models are elegant, convenient, and lucrative: they require mathematical skills on a physicist level, and economists with such skills are usually much better paid than physicists. What is more, such models look very reputable: if quantitative methods are used, then nobody 


\section{Max Urchs}

dares to doubt economics is a real science. And of course, mathematics is the backbone of any decent research in economics. There is no doubt about that.

Nevertheless, there is a methodological worry concerning the use of mathematical methods in economics. It is expressed by the so-called hovercraft-effect, which consists in using high-powered mathematics to hover over the surface of an economic problem without touching it. Abstraction and Idealization beam your models up to an ideal world, leaving economic reality far down. Such econometric models work best under standard conditions, i.e. conditions which are very much idealized and thus far away from the rough reality of a financial crisis. Compare this to a navigator who feels fine in sunny weather, but is unable to navigate in times of storm and high swell. "Not a good navigator" you would say. And similarly with quantitative models designed for good-weather conditions only: If they stop functioning at high swell, i.e. at high market volatility, then they are of little use.

John Coates provides an interesting case: In 2008, the FED met with very limited success in arresting the downward momentum of a collapsing market. Theoretically, it was clear what to do: in the event of a market crash "central banks need only lower interest rates to stimulate the buying of risky assets, which now offer relatively more attractive returns compared to the low interest rates on Treasury bonds". This didn't work. What had happened?

The chronically high levels of cortisol among the banking community have powerful cognitive effects. Steroids at levels commonly seen among highly stressed individuals may make traders irrationally risk-averse and even price insensitive. Compared to the Gothic fears now vexing traders to nightmare, lowering interest rates by 1 or 2 percent has a trivial impact. Central bankers and policy-makers, when considering their response to a financial crisis, have to understand that during a severe bear market the banking and investment community may rapidly develop into a clinical population. [3]

Coates, a cognitive scientist and former investment banker, explains how enduring stress, i.e. a high level of cortisol, interferes with the normally high testosterone levels in investment bankers and makes them sick. They develop a condition called learned helplessness which makes them gun-shy: oddly unable to initiate a trade. The cure would be reduction of any of the two hormone levels, either by long holidays or, perhaps, by chemical castration. Alternatively, one might replace the workmanship altogether. Be that analysis of Coates' valid or not - it looks interesting. And of course, 
no macroeconomic model takes into account hormone levels in individual bankers. These models work well without that, almost anytime. But: exceptions do matter!

Econometric methods are applied mathematics. All applied mathematics has a tendency to degenerate. Or, to put it gently, quantitative models have a tendency to gain formal elegance over time. This phenomenon can be met in all disciplines of science. At the outset of my own encounter with mathematical logic there was the intention to solve a practical problem: to improve man-machine-communication. To that aim, we searched for logic calculi ready to deal with natural language. After some years' effort, we arrived at interesting models. Next we worked hard to make them more elegant, to prove consistent, study alternative versions, classify them, or investigate their mutual interrelations. The intended application faded away. By raising the level of abstraction you get formal models not blemished by all sorts of "real-life" scratches and buckling. That way, however, you arrive at models which are undercomplex (or: oversimplified) for the analysis of the case considered. If you idealize away practical applicability from your quantitative models, then you cannot apply them. No longer do you sincerely intend to apply your findings to investigate the initial specific problem. So what you are doing is no longer applied mathematics - it is just plain mathematics. But it is certainly no pioneering research in mathematics either: a purely quantitative paper from e.g. business studies would hardly be accepted for publication even in a mediocre journal of pure mathematics. Hence, using quantitative models in economics without a reasonable application is not only pointless from an economic point of view - it misses the standards of scientific research.

\section{Complexity's prehistory}

Essential elements of the above criticism were raised as early as the 1920s. Take, for example, John Maynard Keynes' views on model building. In his marvellous book The Claims of Common Sense John Coates extends a panorama of that period in Cambridge. For Keynes, who is badly underestimated as a philosopher of science, Cambridge was the best place to be those days. Besides a group of brilliant young researchers - constituting the Cambridge Circus - there were around some of the greatest philosophical minds of the period: George Edward Moore, Piero Sraffa (a member of the Circus himself), Frank Plumpton Ramsey, and Ludwig Wittgenstein. They all strongly influenced Keynes' ideas on vaguesness. 
Much economic theorizing to-day suffers, I think, because it attempts to apply highly precise and mathematical methods to material which is itself much too vague to support such treatment. ([9], p. 379)

and he continues elsewhere

our precision will be a mock precision if we try to use such partly vague and non-quantitative concepts as the basis of a quantitative analysis. ([10], p. 40)

Keynes did not think this kind of vagueness was problematic. What he had in mind was merely that much of practical experience cannot be reduced to mathematical and logical formalism. Doesn't that remind of Henry Poincare's famous statement?

If we knew exactly the laws of nature and the situation in the universe at the initial moment, we could predict exactly the situation of that same universe at a succeeding moment. But even if it were the case that the natural laws had no longer any secret for us, we could still only know the initial situation approximately. If that enabled us to predict the succeeding situation with the same approximation, that is all we require, and we should say that the phenomenon has been predicted, that it is governed by laws. But it is not always so; it may happen that small differences in the initial conditions produce very great ones in the final phenomenon. A small error in the former will produce an enormous error in the latter. Prediction becomes impossible... ([15], p. 87)

And there is little hope for future improvement. Richard Feynman, the eminent physicist, declared for his own discipline:

Yes! Physics has given up. We do not know how to predict what would happen in a given circumstance, and we believe now that it is impossible, that the only thing that can be predicted is the probability of different events. It must be recognized that this is a retrenchment in our earlier ideal of understanding nature. It may be a backward step, but no one has seen a way to avoid it. [...] So at the present time we must limit ourselves to computing probabilities. We say "at the present time", but we suspect very strongly that it is something that will be with us forever - that it is impossible to beat that puzzle - that this is the way nature really is. ([4], p. 9)

If that is the situation in physics, why should it be any better in the social sciences? Some laws of nature hold for a large variety of systems (i.e. these systems are composed of elements which underlay very different dynamic laws). Modern mathematics is extremely successful in describing real-world situations and processes by quantitative models. But as it comes to the solution of the respective equations, things look dismal: Precise solutions are 
available for very special cases only (or, for very simple systems). So our ability to cope with complicated equations is poor. But modern mathematics does not leave us helpless and blind. Instead, there is an amazing phenomenon: there is order emerging out of chaos. As soon as the number of components is sufficiently large, the summary properties which characterize the system as a whole become in some way predictable. Oftentimes, these predictions are even very easy. There are no hidden commonalities in these systems or magical mutual influences. Just their structural frame is similar: taking together all the weak influences of very many independent factors. The macroscopic behaviour of a big complex system may be almost completely independent of its microscopic structure. That is the very essence of universality.

The remedy is to integrate various perspectives on a phenomenon into one complementary image. Yet such a situation may result in formal inconsistencies during model building. It seems that Keynes had anticipated such an intricacy as well. There was no inconsistency-tolerant calculus available yet, but Keynes' way of reasoning was open for dialectical treatment of complementary components of models. (compare [20], p. 89 ff.) Today the situation is even better: There are ample systems of paraconsistent logic available.

Since all the required elements for complex model structures seem to be existent in Keynes' workshop, why didn't he speak about complexity bluntly? Maybe the answer is very easy: he didn't see it. One facet of complex systems behaviour is the fractal structure of the systems attractor. It was the very shape of the notorious owl-mask then that brought the strangely unstable nature of Lorenz' toy weather system to broader attention. By visualization of the attractor people immediately understood the essence of the phenomenon. What is more, by visualizing the strange attractor the essence of deterministic chaos was displayed. Fractals have been around since the early $20^{\text {th }}$ century. The French mathematician Gaston Maurice Julia tried to draw them by hand in the 1920's. Such an effort, however, is futile. Every single calculation of a function value in the complex numbers leads to another dot on the function's graph. That works fine for linear functions, parabolic curves, or other regular-shaped graphs. Oscillation is much harder. Truly non-linear behaviour is nearly hopeless. Instead of a curve-like graphical representation you end up with an irregular cloud of dots here and there. As before, each dot stands for one value of the function. The dots may crowd together in some areas, may leave other areas empty, and scatter randomly in between. No reasonable structure emerges. It needs high-speed computers and graphic plotters to make a Julia set, 
a Mandelbrot's structure or other fractals appear out of such a cloud. Only millions of dots reveal the graphical beauty of these icons of (some sort of) complexity. One century ago, these pictures did not exist, since there were no technical means available to make them visible.

All you may get by handwork in complexity-visualization is cloudy sets of dots - that is, fuzziness. Complexity in the 1920's was visualized as fuzziness, not as fractals. Limited technological means let us see fuzzy images. So fuzziness, or vagueness, was the coeval appearance of complexity. But a cloud of dots was not appropriate to trigger the sudden insight which was imposed on the viewer when looking at a sharply drawn owl-mask. We did not see it and thus we did not understand its nature. What was visible in the 1920's was merely vagueness.

\section{Computer based simulation}

Things rapidly changed in WWII and immediately after by the joint appearance of a new scientific method and a new research technology. The new method, simulation based on Monte Carlo modelling, and the new technology, non-human (i.e. electronic) computers, developed step by step, stimulating each other mutually.

In the development of simulation as a new method, leading researchers were John von Neumann and Stanisław Ulam, working in the Manhattan Project on the construction of thermonuclear and enhanced-fission weaponry. The Monte Carlo method, so named by Nicolas Metropolis, is mathematical experimenting, based on (very many) random numbers. Its aim is the construction of a simulation, i.e. of the model's dynamics. The random element in Monte Carlo simulation brings that method, according to some philosophers, closer to stochastic physical reality than the usual deterministic differential and integral equations. Computer simulation is therefore a simulacrum for reality, corresponding to nature as no "platonic" infinitesimal modeling ever could. Peter Galison introduced the name "stochasticism" for such a position. Gilbert W. King extends a very fundamental thought concerning the essence of mathematical modeling:

There is no fundamental reason to pass through the abstraction of the differential equation. Any model of an engineering or physical process involves certain assumptions and idealizations which are more or less openly implied in setting up the mathematical equations. By making other simplifications, sometimes less stringent, the situation to be studied can be put directly to the computing machines, and a more realistic model [my emphasis - M.U.] is obtained than is permissible in the medium of differential or integral equations. ([12], p. 2475) 
Working on the simulation of fission processes in a thermonuclear reaction, von Neumann and Ulam drove their computer equipment at capacity limit. They constantly had to invoke assumptions, idealizations, and simplifications. Here is what Ulam confessed to von Neumann:

Everett [Ulam's collaborator - M.U.] managed to formalize everything so completely that it can be worked on by a computer. [...] It still has to be based on guess and I begin to feel like the man I know in Poland who posed as a chess champion to earn money - gave simultaneous exhibitions in a small town playing 20 opponents - was losing all 20 games and had to escape through the window. ([18])

As mentioned above, very many random numbers are required to run a Monte Carlo simulation. No sufficient multitude was available. von Neumann and Ulam robustly decided to produce them straightforwardly by computer simulation and next appropriately expanded the meaning of the term "random number". They displayed a similar kind of nonchalance in day-to-day issues - e.g. deriding Einstein for his concerns about the hydrogen bomb. Obviously, social relations at the Princeton Institute for Advanced Study happened to be distinctly frosty. This did not foster transdisciplinary research. Cybernetics, cognitive science, and artificial intelligence originated somewhere else.

For instance, at the Aberdeen Proving Ground. It was there where Warren Weaver, Claude Elwood Shannon and Norbert Wiener worked on the design of anti-aircraft gun laying systems. Weaver introduced the concept "organized complexity" into mathematic and system theoretic vocabulary in 1948.

They will make it possible to deal with problems which previously were too complicated, and, more importantly, they will justify and inspire the development of new methods of analysis applicable to these new problems of organized complexity ([19], p. 541).

Weaver explains the difference between organized and disorganized complexity by the notorious billards. For three or four balls, says Weaver, one may calculate their position on the table. ${ }^{1}$ For more balls, say ten, this seems to him no longer possible - the problem becomes unmanageable. For many more balls, e.g. one million, on a large billiard table the question has an answer again, by methods from statistical mechanics (provided all required assumptions hold, in particular all balls behave truly disorganized). Still, there was left a region in between. 
The really important characteristic of the problems of the middle region, which science has as yet little explored or conquered, lies in the fact that these problems, as contrasted with the disorganized situations with which statistics can cope, show the essential feature of organization. In fact, one can refer to this group of problems as those of organized complexity. ([19], p. 539)

The rise and prevalence of complexity thought in social science is intimately intertwined with the further development of computing technology. In 1962 Herbert Simon characterized social systems as complex systems: composed of many components, which interact in a non-simple way: "given the properties of the parts and the laws of their interaction, it is not a trivial matter to infer the properties of the whole" ([16], p. 468). In 1971, Brunner and Brewer applied this concept to investigations of the political system. With an eye on the rapidly growing information processing power available, they hoped for the possibility to directly investigate and analyse complex social systems without the usual detours through specialized case studies, aggregations, or statistical methods. "Social systems" according to Brewer ([1], p. 75) "exhibit properties of organized complexity. Their structure contains overlapping interaction among elements, positive and negative feedback control loops, and nonlinear relationships, and they are of high temporal order. These characteristics largely account for the observable diversity of social behaviour."

This turned out to be very much so in the case of psychological, biological, medical, thermodynamic etc. systems as well. Complexity is no discriminator between social and physical systems. So the gap between these two camps was diminished. But, of course, the gap remains. Under laboratory conditions, one may control simple connections between elements. Not so in economics. By idealization we will not arrive at testable connections. Such a procedure rather yields inadequate models that are structurally disconnected from reality. Such models are called "simplistic", another synonym for "undercomplex". Making things simple is a major goal of scientific research. But one has to be careful here. "Make all your theories as simple as possible, but not simpler." 2

So rather than the old slogan "Keep It Simple, Stupid", we should see to it to keep our models Descriptive: from KISS to KIDS - that's progress! But, beware: categories of conformity to the world and of simplicity are no invariants: compact differential equations once were the essence of simplicity, whereas numerical approximation looked complex. Now the machine-readable has become simple and differential equations complex (comp. [6], p. 129). 
Undercomplex models must fail. Simplistic perception of processes can result in preposterous decisions. Insofar, McKinsey \& Company's aged slogan "cutting through complexity" was not very sensible (nor is the recent motto: "dismantling complexity"). Cutting through complexity may result in cutting right into sensible parts of the institutional process. As an actual example of undercomplex, and thus failed, decision making one may take the reaction of German federal officials in the face of refugees deluging Germany last summer. BAMF, the responsible federal institution for migration and refugees was hardly able to cope with overflowing applications from Syria. In that dramatic situation Mr. Frank-Jürgen Weise, head of BAMF, was under hard pressure to speed up the administrative process. In a knee-jerk attempt at "cutting through complexity", he approached the responsible Ministry for permission to skip all singular verifications of Syrian applications and instead to approve them by default. This should result in a huge gain in processing speed. "We will wave through all applications from Syria!" No wonder, this news spread out immediately through all the refugee camps in Turkey and elsewhere and set tens of thousands of people on their march to Germany. This was the "avalanche launched unawares by a careless skier" mentioned in a vitriolic remark by Germany's finance minister. Chancellor Merkel's subsequent kind invitation extended to all refugees was without deeper effect on what happened next.

Another instructive example is the Human Brain Project, one of two flagship projects of European Science. Henry Markram \& Team promised to build an electronic brain within a decade, equipped with all the magic features of a human brain. This megaproject decomposes right now because of being badly undercomplex. For those who remember the decade before last, Hugo de Garis' RoвokoneKo might have been the writing on the wall. There seems to have been a general tendency during the last 70 years: for those who are close to the respective supercomputers of the period, these machines emanate a kind of magical force. (I do not speak about the operating staff, only about philosophically minded heads of the large research teams commanding the use of those computers.) They make people believe that only computation capacity and storage volume - and perhaps more of the same - will let us solve any problem on earth, be it central planning of the Chilean Economy by means of CYBERSYNC or US-Air-Defense in NoRAD. Cutting edge IT, if readily to hand, turns people into Leibnizians. By the way, the Swiss seem particularly disposed to such a delusion of feasibility. It is not only Henry Markram - Swiss academic hospitality also extends to cybernetically minded economists, quite a few of them working at ETH. 


\section{Making use of simulation}

There are a number of regulative ideas in the sciences: simplicity, universality, homogeneity, consistency. They all date back to the Renaissance origin of modern science. I argue for a wider appreciation of the merits of pluralism and complexity.

The promise of Newtonian science, to come up with a unique and precise explanation of the phenomena, seems to be out-dated. Truths about nature and society are rarely simple, universal, and without exception. We cannot hope to always find regularities and causal mechanisms that lead to precise predictions. The world is too complex to describe in a simple way. We need to accept and study in the sciences such phenomena as emergence, contingency, dynamic robustness, and deep uncertainty. ${ }^{3}$

Science, Sandra Mitchell claims ([14]), has traditionally sought to reduce the blooming, buzzing confusion to simple, universal, timeless foundational laws to explain what there is and how it behaves. The essence of the scientific method was a nearly algorithmic procedure for revealing the simplicity underlying the complexity of our daily experience. Reductive explanations, however, founded on simple universal laws, on linear causal models, and predict-and-act strategies do not lead to adequate representation of the specific kind of knowledge provided by many contemporary sciences.

Because of an irreducible multitude of partial causes including unknown components and their effects, and because of the essential uncertainty of open system dynamics, there results a profound uncertainty of knowledge about complex systems' future development. This poses substantial problems to any reasonably precise probability assignment to a future state of the system. If this is right - and I think it is - there are far-going methodological consequences to be drawn. Instead of predict-and-act strategies we need methods of robust planning and continuously adaptive management for deciding in the face of deep uncertainty. However, we do not live in Heraclitus' ever-changing and unknowable world of eternal flux. It is a dappled world, a world that needs pragmatic decisions and enduring willingness to monitor and variegate one's decisions. These changes are already under way. They are oftentimes inspired by thoughts on military leadership.

How far will these changes go? In order to make it a bit clearer, perhaps, I will compare the emerging picture with what happened during the Renaissance ${ }^{4}$. Six hundred years ago times were hard for science: it was undergoing a life-threatening crisis. The crisis was caused mainly by the unwillingness of the scholastic scientists to engage in empirical science and application, to contribute to technological innovations which were badly needed to make 
Joe Blogg's everyday life easier. There were truly extraordinary findings in medieval logic and ontology - but no conscious and deliberate application of those breakthroughs which would make Joe Blogg's everyday life easier. There were truly extraordinary findings in medieval logic and ontology, but there was at the same time an almost complete breakdown of communication between science and society. While scholastic scientists were actually pondering the psycho-physical problem, people in the towns were disgruntled by what they saw as fatuous debates in the ivory tower about angels dancing on a tip of a needle. Science had to regain social acceptance by moving towards applied science. Such a redirection needed more than just another scientific method. Induction came along with a new criterion for scientific evidence. The rules of the game changed to a wide extent. Galileo pushing metal balls off the Pisa tower, though historically wrong, presents a superb icon for the ongoing process of change. His fellow scientists were upset. They refused to even take note of Galileo's experiments. They might have protested: "That is not how we do science! Every student knows the proper method - read the pertinent fragments of the great forerunners, debate the issue among your learned colleagues, and find the received knowledge confirmed, or, in the unlikely case they had erred, correct the error in an addendum. Throwing objects to see them falling down is not what a scientist should engage in." Factually, a new mode of thought was needed to bring about Renaissance science. The new science made a pact with society ${ }^{5}$ :

We, the scientists, will work hard to uncover the most fundamental structures of the world. We will describe them in mathematical language in a Golden Book of nature. Everyman receives a precise and perspicuous picture of reality that lays the foundation for technological progress. We will be sponsored for that.

Call it the Renaissance promise: "At the bottom of nature is a mathematical formula. Scientists will dig it out for you." - Nowadays it looks as if we would not be able to deliver.

Galileo's trouble with the new method reminds me of a meeting of the Polish Mathematical Society in Torun back in 1976, when Roman Duda informed us about the computer-based solution of the Four-Colour-Problem by Appel and Haken. The proof was ugly, indeed: 1936 cases to be checked. No human mathematician would be able to find all those cases, let alone check the computer's solution step by step. We were listening to breathtaking news: one of the eternal mathematical problems was finally solved. But the atmosphere in the lecture theatre was not friendly, not at all. My distinguished teachers were bouncing up and down (in those days I was 
still an undergraduate, a rather perplexed one, watching that scene): "That is not mathematics! It is no solution at all!" A new method always has hard times before being accepted. You all know Max Planck's bitter remark: "A new scientific truth does not triumph by convincing its opponents and making them see the light, but rather because its opponents eventually die, and a new generation grows up that is familiar with it." In the case of computer-based maths it was not nearly that bad. It took far less than one generation for simulation to gain acceptance. When I came back to Torun University twenty years later to start - together with Jerzy Perzanowski - cognitive science at UMK, computational mathematics was already an established discipline. Mathematicians might not have liked what von Neumann, Ulam, Teller, and other bomb builders did at Princeton IAS. But they could hardly deny that these chuff guys were tremendously successful with what they did - computer-based simulation really worked for the Allied victory.

What about the outcome of these developments for science? We are experiencing another expansion of the field of scientific activity: future science will approach a realm of chaos and apparent randomness which was not plumbable hitherto. And again, it will apply a newly-created method: massive simulation (see, e.g. [13]), based on state-of-the-art information processing technology. ${ }^{6}$ What was induction and the swerve towards the empirical world in Renaissance times, today is simulation and the focus on the domain of complex systems, formerly known as the swampland of fortitude. This is the new area conquered by science - the mezzo level characterized by deep, causal uncertainty. Universality, power laws, stylized facts built trust in the feasibility of this attempt at conquest. Valuable achievements of traditional science will be preserved. In particular, the central role of quantitative methods outlasts, but it will be flanked by massive simulation. Mathematics has been given powerful new language: algorithms and big data structures, and a new kind of mathematical reality is evolving.

"The complex systems revolution", says Cliff Hooker, "is currently exploding through science, transforming its concepts, principles, methods, and conclusions. It is also transforming its disciplinary structure, both creating new, distinctive 'complexity' disciplines, such as climate science, systems and synthetic biology, and self-assembling/repairing and social robotics, and transforming older disciplinary relations, e.g. between developmental biology, psychology, and sociology. This revolution is creating a plethora of new problems and challenges for the foundations and philosophy of science. These have a special intellectual appeal, because the foundations of the science of complex systems is itself still being invented. This dual revolution 
in science and philosophy is the most important large scale development in scientific cognition for a century. It invites the urgent attention of scientists and philosophers alike." ([8], p. 902) This means good times for young researchers.

\section{N O T E S}

1 Two bodies are safe. And a short time frame, i.e. few collisions: Already after 8 collisions the gravitational force exerted by the billard player must be taken into consideration.

2 That witticism, usually ascribed to Albert Einstein (with little reason, however; compare [17]), has more than just a grain of truth.

3 Comp. [5], p. 95ff.

4 The rest of this paragraph is an extraction from [17].

5 This is metaphorical, do not search the archives!

6 Actually, there are many candidate names around. Beside massive simulation we find computer based simulation, scientific computing, calculation as theory, reverse engeneering of nature by numbers, and perhaps more.

\section{R E F E R E N C E S}

[1] Garry D. Brewer, Politicians, Bureaucrats, and the Consultant: A Critique of Urban Problem Solving, Basic Books, 1974.

[2] John Coates, The Claims of Common Sense: Moore, Wittgenstein, Keynes and the Social Sciences, Cambridge University Press, 1996.

[3] John Coates, The Hour between Dog and Wolf: Risk Taking, Gut Feelings and the Biology of Boom and Bust, Fourth Estate, 2012.

[4] Richard Feynman, The Feynman Lectures on Physics, vol. 1, "Quantum Behaviour", http://www.feynmanlectures.caltech.edu/I 37.html

[5] Stanisław Flejterski, Max Urchs, Elementy filozofii i metodologii nauk ekonomicznych, edu-libri, 2015.

[6] Peter Galison, "Computer Simulation and the Trading Zone", in: Gabriele Gramelsberger (ed.) From Science to Computational Science. Studies in the History of Computing and its Influence on Today's Sciences, diaphanes, 2011, 97-130.

[7] Gabriele Gramelsberger (ed.) From Science to Computational Science. Studies in the History of Computing and its Influence on Today's Sciences, diaphanes, 2011, 97-130.

[8] Clifford Hooker, Philosophy of Complex Systems, as: vol. 10 of the Handbook of the Philosophy of Science, Elsevier, 2011.

[9] John Meynard Keynes, "Appendix: Variorum of Drafts of the General Theory and the Final Text", in: Collected writings, vol. 14, Royal Economic Society, 1978 . 
[10] John Meynard Keynes, "The General Theory of Employment, Interest, and Money", in: Collected writings, vol. 14, Royal Economic Society, 1978.

[11] John Meynard Keynes, "The Nature of Inductive Arguement Continued", in: Collected writings, vol. 8, Royal Economic Society, 1978.

[12] Gilbert William King, "Monte Carlo Method for Solving Diffusion Problems", in Industrial and Engineering Chemistry 43, 1952, 2475-2478.

[13] Johannes Lennard, Mit allem Rechnen. Zur Philosophie der Computersimulation, De Gruyter, 2015.

[14] Sandra Mitchell, Unsimple Truths. Science, Complexity, and Policy, University of Chicago Press, 2009.

[15] Henry Poincare, Science and Method, Thomas Nelson and Sons, 1914.

[16] Herbert Simon, "The Architecture of Complexity", Proceedings of the American Philosophical Society 1962, vol. 106, no. 6, 467-482.

[17] Max Urchs, "Just Complexity", in: Maria Carla Galavotti et al (eds.) New Directions in the Philosophy of Science, Springer, 2014, 203-219.

[18] John von Neumann Correspondence, Manuscript Division, Library of Congress, box 22 (17 March 1950).

[19] Warren Weaver, "Science and Complexity", American Scientist 1948, vol. 36, no. $4,536-544$.

[20] Weber, Eric; van Bouwel, Jeroen, "Coping with Inconsistencies", Logic and Logical Philosophy 2005, vol. 14, no. 1, 89-101. 